\section{God does not need science . . .}

SIR-I should like to respond to some features of your article "Setback for creation science" (Nature 327, 643; 1987).

"Common sense" played no part in the US Supreme Court's decision against Louisiana's "Balanced Treatment Act", because "common sense" over-whelmingly supports the concept of an omnipotent creator over an ailing theory of evolution.

The "blend of fancy and whimsy" Nature refers to as creationist evidence was characterized by the two dissenting judges, Justice Antonin Scalia and Chief Justice William Rhenquist, as "the large body of uncontested evidence presented on behalf of creation science". As for the Supreme Court having "done the decent thing", it merely upheld one covert religious system (darwinism, or atheistic secular humanism) over an overt system (creationism).

The "uncertainties of the process of inference" vis-à-vis darwinism were recognized as soon as Darwin proposed his conjecture and even earlier when Alfred Russell Wallace preempted Darwin on darwinism. They are now being conceded belatedly by an embattled 128-year-old theory. I disagree that "contradictory evidence" against darwinism "is hard to find". We are drowning in it. Colin Patterson, senior palaeontologist at the British Museum, referred to molecular homology (a latter-day prop of darwinism) as "antiknowledge" generating "anti-theory". $\mathrm{He}$ referred to so much "slop" in the data of molecular homology and pointed out that its processing had been "massaged with evolutionary theory".

Many of the founders of our science (for example Newton, Pasteur and Maxwell) believed in the same creator as the creation scientists Nature labelled as "charlatans". Nature errs seriously when it says that the conflict in reconciling evolution with religious beliefs is "not unavoidable". It is unavoidable. Religion predicates a creator, whereas darwinism was contrived to negate him. Creationism and darwinism constitute the opposing poles of the ultimate cosmic axis of God versus Satan, in the sense of the creator being the antithesis of the destroyer. This is theology, not science, but it underlies scientific view of origins.

On Nature's assertion that people who believe in Genesis are "gullible", it takes more gullibility to believe in darwinism than in Genesis. Darwin himself said that "to suppose that the eye . . . could have been formed by natural selection, seems, I freely confess, absurd in the highest degree".

Surely Nature does not seriously believe that people are "mischievous" when they decline to follow the criteria that other

\section{people readily accept.}

Creationism is an ancient idea intuitive to aeons of mankind. It is no more untenable a concept than the postulate of modern physics that matter can be created from nothing. Creationism may be a disgusting idea to many (for theological, political or personal reasons), but it has a clear right to a hearing on its merits as a plausible explanation of origins, on at least a par with darwinism. It becomes instantly implausible if, and only if, one is covertly (or otherwise) obliged to sustain atheism as a sine qua non. Finally, one bolsters such an a priori position by invoking a deus ex machina such as darwinism.

Incidentally, Darwin's only degree was in theology, not in science. Although he was "the naturalist" aboard the Beagle, he had no scientific training nor credentials. Yet, theologians who defend creationism are ridiculed by evolutionists for not being scientists.

God does not need science to prove His existence. In fact, in Christianity, the only prescribed way to the godhead is not by science, but by a little child's faith. Atheism, on the contrary, cannot sufficiently justify its existence on something as nebulous and negative as mere nonbelief in the creator. It desperately needs credentials, even pseudoscientific ones.

Reginald T. Chelvam

Houston, Texas 77008, USA

\section{A sideways look}

SIR-A.C. Dornhorst (Nature 329, 758: 1987) cautiously suggests that El Greco suffered from unilateral astigmatism. He postulates that the artist viewed the subject with the abnormal (astigmatic) eye, but the canvas with the normal one. This is unlikely: severe unilateral astigmatism results in amblyopia - if he had used this eye to view the subject it would have been so defective he wouldn't have bothered to paint at all!

University of Leicester,

A.R. Fielder M.J. Moseley

Department of Ophthalmology,

Clinical Sciences Building,

Leicester Royal Infirmary,

PO Box 65 ,

Leicester LE2 7LX, UK

Sir-If El Greco's astigmatism were unilateral, the other eye being 'normal', he would doubtless have seen the world more clearly with the better, emmetropic eye, and would not have produced astigmatic pictures. If the fellow eye were highly myopic, however, the astigmatic eye having a spherical equivalent of approximately zero, he would have been obliged
1740 West 27th Street, Suite 301, to use the astigmatic eye to view his models, who would then appear distorted, while faithfully reproducing this perceptual distortion on the canvas using the other, spherically myopic eye. It is true that this would be an unusual state of refractive affairs, but then El Greco was an exceptional man.

It is not necessary to postulate this implausible form of anisometropia to explain his painting, however. If both eyes were astigmatic he would have developed meridional amblyopia ${ }^{1}$ which would effectively blur lines in the axis of the more ametropic meridian, both in the world he viewed and in the one he represented on canvas, generating the predilection for lines and axes of a particular orientation, to the exclusion of their less clear perpendiculars, which distinguishes his work.

Philosophical nonsense it may have seemed, but the ophthalmologist's proposition had its origin in the viscous world of perceptual aesthetics, where logic follows the artist's private lights.

The Old Bakehouse,

Nicholas Evans

Bruntingthorpe,

Lutterworth,

Leicester, UK

1. Gwiazda, J., Bauer, J., Thorn, F. \& Held, R. Clin. Vision Sci. 1(2), 145-152 (1986).

\section{Human genome sequence}

SIR-The proposed project, in the United States, to sequence the entire human genome, has long-term implications that are disconcerting. This project would require the establishment of a large central bureaucratic organization to oversee and coordinate the effort, and such bureaucracies do not voluntarily dissolve themselves when the task for which they were originally set up has been accomplished. Instead, they find something else to do, much as NASA (National Aeronautics and Space Administration) proposed the ill-fated space shuttle, to justify its continued existence, once the task of 'beating the Russians to the Moon' had been accomplished. Thus the genome project, once initiated, would probably lead to a permanent drain on manpower and resources from other areas of biomedical research and a permanent tilt towards 'big science' of which high-energy physics is the best example. Anyone who knows how high-energy physics research is currently done, knows how much of a disaster that would be.

Robert J. Yaes

Albert B. Chandler Medical Center, Department of Radiation Medicine, University of Kentucky,

Lexington, Kentucky 40536-0084, USA 